\title{
Development and Characteristics of the Therapeutic Alliance in a Short-Term Dynamic Psychotherapy: A Descriptive Case Study
}

\author{
Diego Rocco ${ }^{1 凶}$, Alessandro Gennaro ${ }^{2}$, Francesco De Bei $^{3}$, Diego Zanelli ${ }^{1}$, and Valeria Condino ${ }^{4}$
}

\begin{abstract}
Despite the long tradition in psychotherapy research literature concerning the role of therapeutic alliance (TA), both in terms of process and outcome in clinical intervention, little is known about its specific characteristics in short term dynamic psychotherapy (STDP). Accordingly, the main aim of the present work is to focus on the formal features of TA in a good outcome STDP. We applied the Collaborative Interaction Scale (Colli \& Lingiardi, 2009) to verbatim transcripts in order to track macro and micro evolution of TA while considering the interplay of both therapist and patient contributions. Data were analyzed in terms of TA general trend, TA climate onset and high impact session TA characteristics. Results sustain the STDP theory of technique (Davanloo, 1990) concerning the general process, the onset features and patient therapist interplay from a TA perspective.
\end{abstract}

Keywords: therapeutic alliance, therapeutic process, short-term psychotherapy, outcome

In the last ten years a new generation of research has focused on the study of clinical dynamics connected to the development of the therapeutic alliance (TA), and in particular to the way the therapeutic alliance could be seen as a process resulting from the continuous interplay of patient-therapist's ruptures and resolutions. Such efforts represent an attempt to integrate specific and non-specific factors in evaluating the quality of the therapeutic relationship (Ackerman \& Hilsenroth, 2001, 2003; Safran \& Muran, 2000). Current research has focused on the role that TA assumes in the whole therapeutic process, and on its development and management. TA studies, in line with Bordin's definition of TA (Bordin, 1975, 1979), not only assume a "static" perspective (in other words a global vision of TA con-

\footnotetext{
${ }^{1}$ Department of Philosophy, Sociology, Education and Applied Psychology, University of Padua.

${ }^{2}$ Department of History, Society and Human Studies, University of Salento.

${ }^{3}$ Department of Psychology, University of Turin.

${ }^{4}$ Department of Dynamic and Clinical Psychology, Sapienza University of Rome.

$\square$ Correspondence concerning this article should be addressed to Diego Rocco, University of Padua, c/o LIRIPAC, Via Belzoni, 80, 35100 Padova. E-mail: diego.rocco@unipd.it
}

cerning a single session or a group of sessions), but also focus on its dynamic, co-constructed nature, that is the specificity of the TA process seen as the analysis of ruptures and corresponding resolutions (Safran \& Muran, 2000).

On an empirical level there are now several studies concerning the relationship between ruptureresolution interplay in TA and psychotherapy outcome. For example, a study by Muran et al. (2009), randomly assigned a sample of patients to three different time-limited psychotherapies for personality disorders (cognitive-behavioral, brief relational and short-term dynamic). The results indicated that lower rupture intensity and higher rupture resolution are associated with better ratings of the alliance and session quality, and lower rupture intensity predicts good outcome on measures of interpersonal functioning. Moreover, based on the empirical evidence available, the repair of alliance ruptures has been included in a list of promising and probably effective treatment principles (Norcross, 2011). In their research, Muran et al. (2009), in addition to advocating the importance of rupture and repairs in the alliance, shed light on the course of the alliance during treatment. The ability to effectively manage a rupture by resolution would, in other words, go further than simply allowing the pro- 
cessing to continue, and would be a central aspect of the process itself (Safran \& Muran, 1998, 2000). These studies have examined the hypothesis that in the development of TA there are well-defined and identifiable stages. A study by Golden and Robbins (1990), for example, showed that even if the therapist is engaged in maintaining the TA at a good and constant level, in the middle part of the therapy, patients show an increase in negative feelings, attitudes and behaviors and consequently a reduction in TA. Accordingly, most theories concerning the development of TA throughout treatment have centered on the idea that the alliance moves through a high-lowhigh pattern over time. For instance, Mann (1973) proposed three phases of TA development. The first phase of treatment is characterized by a growing strong alliance, the second, or middle phase, is affected by client resistance and dissatisfaction, followed by a return to a stronger and more stable alliance during the last phase of treatment. Bordin (1979) proposed that the TA would move in a cyclical manner through development, decay, and repair over the course of therapy. In the early 1990s new research emerged that has begun to examine patterns of alliance development over the course of treatment, and how variations in alliance development impacts therapy outcome. These studies reveal the high-lowhigh pattern of alliance development that had been proposed by theorists (e.g., Gelso \& Carter, 1985; Mann, 1973).

The low value of TA in the middle phase of therapy can assume mainly two specific trends: a Vshaped trend, with a more defined crisis moment, and a U-shaped trend (e.g., Golden \& Robbins, 1990; Horvath \& Marx, 1991), in which the TA reduction was distributed across a certain number of sessions belonging to the central phase of the therapy. Interestingly, the analysis of TA trends in good outcome psychotherapies have revealed a wide assortment of alliance patterns within their research samples, including: stable and linear patterns (de Roten et al., 2004; Sexton, Hembre, \& Kvarme, 1996), linear and curvilinear patterns (Kivlighan \& Shaughnessy, 1995; Patton, Kivlighan, \& Multon, 1997), linear and tear-and-repair patterns (Stevens, Muran, Safran, Gorman, \& Winston, 2007), stable, linear, and quadratic patterns (Kivlighan \& Shaughnessy, 2000), and stable, linear, decreasing and mixed stable/linear patterns (Stiles et al., 2004). According to such results Castonguay, Costantino, and Grosse-Holtforth (2006) claim that the kind of the shape of the alliance trend can depend on the specific patient.

The interest of literature in the TA and its trend is not currently a core research topic in short-term dynamic psychotherapy (STDP), despite the acknowledged role of TA from the viewpoint of theory of technique, and despite the role that TA assumes in STDP-specially in "high impact sessions" (Raue, Goldfried, \& Barkham, 1997), that is, sessions characterized by patient's challenging of the therapeutic bond and therapist active management of alliance ruptures. STDP actively solicites therapeutic alliance from the very first few sessions (early alliance) with the aim of encouraging, from the beginning of the therapy, the emergence of a large amount of clinically significant material (Flegenheimer, 1982). Unlike a psychoanalytic approach, the creation of "the set of rational attitudes that the patient has toward the analyst" (Greenson, 1967, p. 163) - namely what feeds the TA on the patient's part-cannot develop in an STDP, due to several reasons associated with specific STDP setting features, that is the reduced number and frequency of sessions, the modality of time passing, analytic silence and so on (Greenacre, 1954).

Accordingly, Gaston, Piper, Debbane, Bienvenu, and Garant (1994) have pointed out that in an STDP the therapeutic alliance contributes in a significant way only to symptom reduction while, in a long-term therapy, it also contributes to interpersonal problem resolution (see also Despland et al., 2009; Owen \& Hilsenroth, 2011). This study, however, used the California Psychotherapy Alliance Scales (CALPAS; Marmar, Weiss, \& Gaston, 1989), which despite its usefulness for TA evaluation provides only a macro analysis of TA without offering evidence of the constituent micro aspects of the process, which would be useful in order to better define the impact of TA on interpersonal problem resolution. In another work, Kramer, de Roten, Beretta, Michel, and Despland (2009) studied the patterns of TA in 50 STDPs of up to 40 sessions; the patterns observed varied from stable, to linear, to quadratic growth, but also in this case the instrument used to measure the alliance, the Helping Alliance Questionnaire (HAq-I; Alexander \& Luborsky, 1986) provided a global value of alliance and did not provide an analysis of microprocesses.

In view of the lack of studies able to integrate wide trend analysis and microprocesses analysis, the present study aims to analyze both the global characteristics of TA in a good outcome STDP and its unfolding from a microprocessual viewpoint in order to offer a better understanding of the link between this construct and a good clinical outcome.

It is worth underlining that the present work does not gather TA information using a post-session questionnaire completed by the patient, by the therapist or by an observer, but collects it from the transcription of the sessions and their subsequent rating by trained judges. This criterion was chosen following Colli and Lingiardi's (2009) view: "Using self-reports patients could not remember the effort made by the therapist to overcome a rupture because they were in an angry state after the session; other patients could acknowledge with difficulty the idea that the therapist did his or her job in creating a negative atmosphere; others might simply dissociate emotionally marked relational episodes after the session" ( $\mathrm{p}$. 719). The use of a rating scale applicable to session transcription undoubtedly has the limitation of being 
time-consuming (i.e., specific training for utilizing the scale is needed and the evaluation process requires a large amount of time), but on the other hand this way of analyzing TA allows micro-analytic observations concerning the characteristics of therapeutic process that could be used from a clinical point of view. In other words, using this methodology makes it possible to explore in greater depth the development of TA dynamics, linking the single clinical exchange to an output. Moreover, using the micro TA data as a starting point, it is possible to obtain a global value of TA for the whole session.

In order to achieve its aim the present work will address three main aspects:

(1) Firstly we intend to analyze the clinical process in terms of both patient and therapist's contribution to the maintenance of a collaborative relationship. Specifically, according to the above mentioned literature, we hypothesize that the collaborative level of the therapeutic relationship (TR) will not follow a linear trend, but we expect that it will draw a $\mathrm{V}$ or a U-shaped trend because the clinical valence of TA does not depend on the absolute value of the collaboration level, but on the capacity of the therapeutic couple to face and to elaborate the unavoidable critical phases of the therapeutic relationship (Hypothesis 1).

(2) Secondly, according to the STDP theory of technique concerning TA, we hypothesize that there will be a specific TA pattern in the initial phase which will differ with respect to the patterns of the subsequent phases (Hypothesis 2). We expect that the first phase of the treatment will be characterized by the therapeutic dyad seeking synchronization in TA, thus reflecting the therapeutic dyad's efforts and difficulties in constructing a collaborative climate. In other words, at the beginning of the treatment we expect that the ruptures by the patient will not be synchronized with the therapist's attempts at resolution, assuming that their synchronization would be an expression of a good collaborative climate, whereas in the following phases we expect that such synchronization will be present.

(3) Finally we conducted an in-depth analysis of a "high impact session" (Raue et al., 1997). We expected that this kind of session would not be characterized by a high absolute value of TA (we expect that it will have a mean TA value), but rather by a specific dynamics, consisting of significant fluctuations throughout the session, with an alternation of ruptures - marked by low collaborative level of the TA-and the therapist's intervention of reparation (Hypothesis 3). More specifically, we expect that such fluctuation will occur in the first part of the session. In doing so, it paves the way to (ri)enforcement of the TA, namely an increase in the collaborative level of $\mathrm{TA}$ in the second part of the session.

\section{Method}

\section{Client}

The outpatient, Mr. C, was a 21-year-old male university student, of medium socio-economic level, who reported a sexual problem he had had for three years and some difficulties in relationships as well. According to the psychotherapist's opinion and the information coming from the SWAP-200, the patient had a neurotic level of functioning, with a dependent structure of personality.

Mr. C's treatment was considered successful (see Rocco, De Bei, \& Mariani, 2013), in line with changes in symptom profile measured by the Symptom Check List (SCL-90-R; Derogatis, 1983), and personality profile, assessed by the Shedler-Westen Assessment Procedure (SWAP-200; Westen, Shedler, \& Lingiardi, 2003).

\section{Therapy and therapist}

The whole intervention lasted 14 sessions: the therapist used the first 4 sessions in order to have a clear outline of the patient and to design a proposed therapy which was carried out through 10 weekly sessions. The treatment was an STDP approach based on the work of Davanloo (1990), integrated with suggestions from Fosha (2000), in a Psychological Service in Northern Italy. In the STDP intervention model, the therapist starts to deal with the alliance problem when the patient, after many questions and clarifications, starts to show some signals of negative transference (for this point see De Bei \& Montorsi, 2013). At this point the therapist makes an explicit reference to the importance of having the patient as an ally against the dysfunctional modalities emerging in the psychotherapeutic relationship. It is possible to say that in Davanloo's method the reference to the alliance arises from a crisis that sees the therapist as an active and aware participant. Unconscious TA is contrasted and put into relation with the resistances on the one hand and transference feelings on the other. Alliance, resistances and transference are closely connected in the intervention model considered, and the attention towards the good TA signals gives the therapist information concerning the intensity of pressure that he can apply on the patient's feelings. Some sessions, for instance therapy session seven, last one and a half hours, and this particular duration is in line with the STDP model, and related techniques, proposed by Davanloo (1980, 1990). The psychotherapy sessions were held by a middle-age male psychotherapist with over ten years experience in the STDP approach.

\section{Measures}

To enable the analyisis of the intense clarification and confrontation processes and the continuous monitoring of the patient's inner state that the therapist has to undertake, a very precise tool is required that can detect the sudden fluctuations of quality and intensity of 
TA. Given these characteristics of the therapeutic process in the STDP under examination, and in accordance with our research aims, we adopted Colli and Lingiardi's Collaborative Interactions Scale (CIS; Colli \& Lingiardi, 2009). The CIS is a transcript-based rating scale allowing the evaluation and quantification, through the precise analysis of each single clinical exchange, of the patient and therapist relationship in terms of TA.

The CIS is composed of 41 items grouped into two main scales: the first concerns both the rupture process and the collaborative process of the patient (CIS$\mathrm{P})$, the second concerns the positive and/or the negative interventions by the therapist (CIS-T). The CIS-P is divided into Direct Ruptures Markers (DRMs; 9 items), Indirect Ruptures Markers (IRMs; 9 items) and Collaborative Processes (CPs; 3 items).

In CIS-P the Direct Ruptures Markers "are characterized by an aggressive and accusatory statement of resentment or dissatisfaction in regard to the therapist or some aspect of the therapy process" (Colli \& Lingiardi, 2009, p. 723), while an Indirect Ruptures Marker is present "when the patient indirectly expresses a form of emotional disengagement from the therapist, from some aspects of the therapy process, or from his or her internal experience" (Colli \& Lingiardi, 2009, p. 723). An example of a Direct Ruptures Marker item is "patient criticizes therapist as a person or for his/her competence," and an example of an Indirect Ruptures Marker item is "patient changes topics or tangentially answers to therapist intervention." The Collaborative Processes "include when the patient brings salient and significant themes, shares intimate and salient information with the therapist, self-observes his or her reactions, or works actively with the therapist's comments" (Colli \& Lingiardi, 2009, p. 723). The Collaborative Processes can be expressed in different ways: "patient speaking about his own feelings," "patient gives new information," etc.

The CIS-T is divided into two subscales, the first concerns Positive Interventions (PIs; 12 items) including both collaborative intervention and the resolutions enacted by the therapist, the second concerns Negative Interventions (NIs; 8 items) describing the negative contribution to the alliance by the therapist. A Positive Intervention by the therapist might be an attempt to make explicit the appearance of an Indirect Rupture Marker by the patient facilitating, for instance, the expression of negative feelings. In order for an intervention to be coded as a Positive Intervention, it must be "emotionally attuned, focused on patient experience, and linguistically clear" (Colli \& Lingiardi, 2009, p. 723). Typical examples of Positive Interventions are "therapist focuses on the here and now of the relationship," or "therapist makes a clarification."

The therapist's Negative Interventions are instead "not emotionally attuned, not focused on patient concrete experience, or not linguistically clear" (Colli \& Lingiardi, 2009, p. 723). The Negative Intervention might take different forms, for instance "therapist is hostile" or "therapist seems doubtful about strategies."

The basic evaluation unit of the CIS is the individual speaking turn of either the patient or the therapist: raters assess the presence of Direct Ruptures Markers, Indirect Ruptures Markers or Collaborative Processes in patient's speech and of Positive Interventions or Negative Interventions in the therapist's speech. Rupture intensity and collaboration level intensity are evaluated on a 3-point Likert scale (values from -1 to -3 for ruptures; values from +1 to +3 for collaborations; it is not possible to assign a null score). Further information concerning the scoring can be found in Colli and Lingiardi (2009).

A CIS manual, containing a list of items for each scale, was provided to each rater. For both patient and therapist interventions, the identification of the right item from the manual must be done considering the wider contest of the intervention. For instance, a patient who is communicating a disagreement to the therapist, but is able to place it in relation to his past behavior with his parents, is not scored as a rupture marker but as a Collaborative Process. Similarly, a resolution from the therapist that, even if conceptually correct, is expressed with irritation, will be scored as a Negative Intervention and not as a Positive Intervention.

For the particular psychotherapy considered, an important clarification is necessary. Since we are considering a STDP, characterized by a technique that foresees a certain amount of pressure on the patient's feelings (sometimes a great deal), it is necessary for the rater to be aware of this. This awareness avoids the interpretation of an intervention as being negative (for instance classifying it using the Negative Intervention item "therapist seems to press patient on specific topic") when in fact its nature is closely related to the technique being applied.

\section{Procedure}

All 14 sessions of the psychotherapy were analyzed. The sessions were audio recorded, with the patient's informed consent, and subsequently transcribed verbatim following the Italian rules for transcription (Mergenthaler, Freni, Giampieri, \& Ferrari, 1998).

The scoring was completed on the verbatim transcription of the sessions and, if necessary, the judges listened to the audiotapes. ${ }^{1}$ The scoring was blind (i.e., raters did not know the sequence of the sessions), thus avoiding an expectation effect concerning different phases of the therapy.

Four different judges were involved in scoring the sessions. The first two, expert judges, had completed a five-year degree in psychology (undergraduate degree

\footnotetext{
${ }^{1}$ Listening to the audiotapes was particularly useful, and sometimes indispensable, to obtain information concerning the emotional tone that accompanied both the patient's and the therapist's interventions (this was particularly true for those moments in which the therapist placed pressure on the patient's emotions).
} 
plus a two-year Master's degree in clinical psychology) and had experience in clinical research. They obtained the training certification as expert judges after having completed an official intensive course concerning CIS that foresees the coding of a wide number of transcriptions and the study of the coding manual. The second two judges (that we called non-expert judges) have an undergraduate degree in psychology without previous experience in clinical research. They completed a similar training to that of the expert judges.

Each session was coded separately by an expert judge and a non-expert judge. The inter-rater agreement was measured by means of the intraclass correlation coefficient (ICC; Shrout \& Fleiss, 1979) for each session and for both the scales CIS-P and CIS-T. The global agreement between judges was .78 for CIS-T and .83 for CIS-P, representing a strong agreement (Landis \& Koch, 1977).

Before coding, the judges were informed about the characteristics of the active technique adopted by the therapist underlining, for instance, that pressing the patient on a specific topic was not always a Negative Intervention (as the third item of the Negative Intervention scale envisages: "therapist seems to press patient on specific topic"). In order to distinguish the Negative Interventions from the technical interventions particular attention was given to the clarity of the intervention, the affective attunement with the patient's feelings and how the therapist focused on the patient's experience.

Once the CIS had been applied to all therapeutic transcripts, in order to evaluate the clinical process trend in terms of TA quality (Hypotheses 1) a Session Quality Index was developed for each session. The Session Quality Index is calculated as the ratio between the total amount of non collaborative and collaborative interventions (of both patient and therapist) for each session:

Session Quality Index $=($ Direct Ruptures Marker + Indirect Ruptures Marker + Negative Intervention) / (Positive Intervention + Collaborative Process).
This index has been interpreted as highlighting the quality of the session in terms of collaborative level of the therapeutic relationship: the higher the index, the lower the collaborative level of the therapeutic relationship, and, as such, the quality of the session, while a lower Session Quality Index highlights a higher level collaborative session. Then, in order to test if TA evaluated in the early stage of the process differs from the subsequent stages (Hypothesis 2), a rank correlation was calculated between patient non collaborative intervention (Indirect Ruptures Marker + Direct Ruptures Marker) and therapist Positive Intervention, given that the relationship between these variables is an expression of the attunement between patient and therapist in building a good collaborative climate. We decided to adopt a 4-session window, which could take into account both the development of the therapeutic proposal (first four consultation sessions) and the therapeutic action. The latter was divided into two parts (from session 5 to session 8, and from session 9 to session 12), allowing the identification of two final sessions.

Finally (Hypothesis 3) in order to obtain evidence about the working of TA inside the session, a high impact session (session 7) was annotated in terms of patient and therapist contributions to the clinical process. Session 7 was chosen on the basis of the therapist describing it as being characterized both by the therapist strongly directing the patient towards his feelings, and the related presence of a large amount of confrontations and defense mechanisms, as well as the intense contact of the patient with emotions not previously expressed.

\section{Results}

\section{Hypothesis 1: Clinical process and TA global quality}

Concerning the global quality of TA, Figure 1 displays the Session Quality Index values for each of the 14 sessions.

The Session Quality Index fits a quadratic curve
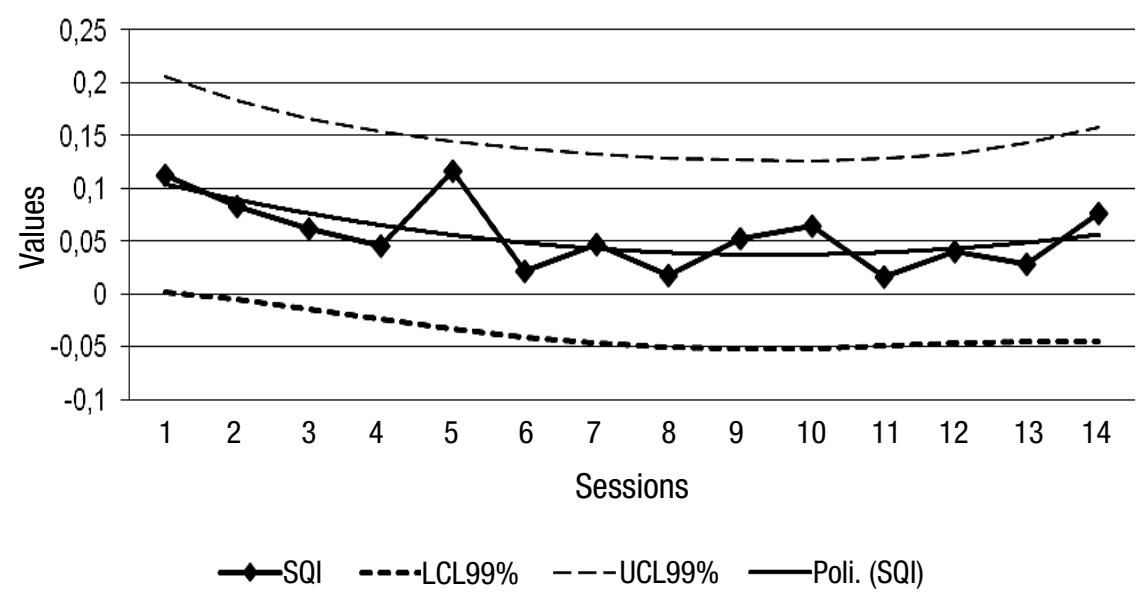

Figure 1. Use of communicative intentions at different stages of therapy. SQI $=$ Session Quality Index. LCL99\% $=$ Lower Confidence Limit. UCL99\% = Upper Confidence Limit. Poli. (SQI) = Fitted SQI Quadratic Curve. 
Table 1. Values of Spearman's correlations between patient's non collaborative intervention and therapist's positive interventions

\begin{tabular}{cc}
\hline Sessions & $R$ \\
\hline $1-4$ & $-1.000^{* *}$ \\
$5-8$ & $.945^{*}$ \\
$9-12$ & $1.000^{* *}$ \\
$13-14$ & n.s. \\
\hline
\end{tabular}

${ }^{*} p<.05 .{ }^{* *} p<.001$.

described by the equation $y=0.0009 x^{2}-0.0177 x+$ 0.1209 , and even though $R^{2}$ is relatively small, .042 , the Session Quality Index for each session was within the $99 \%$ esteemed confidence.

Specifically, in the first part of the process (session 1-4), the Session Quality Index decreases, and, in so doing, shows an increase in collaborative interventions. This trend is different from both the central parts of the clinical action (sessions 5 to 8, and sessions 9 to 12), representing the core of STDP, and from the final sessions (session 13 and 14), where the Session Quality Index, even when fluctuating, tends to become stable and then to subsequently rise again.

\section{Hypothesis 2: Early alliance and outcome}

Concerning hypothesis 2 correlations between patient non collaborative intervention (Indirect Ruptures Marker + Direct Ruptures Marker) and therapist Positive Intervention were compared in the identified time windows. Due to the low number of cases a non-parametric correlation (Spearman's $r$ ) was chosen.

As shown in Table 1, the correlation between patient non-collaborative interventions and therapist positive interventions are meaningful in three out of the four stages identified, and the direction of the correlations changes between the first phase (session 1-4) and subsequent phases.

\section{Hypothesis 3: Trend of a "high-impact session"}

To verify hypothesis 3 we analyzed session 7 , which belongs to the central part of the therapy, considering the Patient Collaborative Levels and the Therapist Collaborative Levels. Figure 2 shows the level of collaboration of both the patient and of the therapist in each verbal unit (the basic unit of the CIS, i.e. the individual speaking turn of either the patient or the therapist) of the session considered.

The first part of the session (first 64 verbal units) is characterized by an intense activity of patient ruptures and, at the same time, by most of the resolution interventions of the therapist (even if they are not followed by a collaborative process by the patient). Beginning from verbal unit 64 the situation changes: despite the evidence of some ruptures of the therapeutic alliance (i.e., verbal units 90, 92, 136, 199, 213 and 218) the patient expresses many collaborative processes (for example verbal units $74,82,85,86,87,88$, etc.). The Session Quality Index value of this session is average in comparison with the values of the other session, as can be seen in figure 1.

\section{Discussion}

In this study our main aim was to focus in detail on the characteristics of the TA in a good outcome STDP both at a micro and a macro analytical level. The TA, evaluated in terms of the collaborative value of the clinical sessions, shows a quadratic trend. In the first four sessions the sharp decrease in Session Quality Index could be seen as the expression of patient and therapist commitment in the development of a collaborative therapeutic relationship. Once this kind of relationship reaches high collaborative levels, it becomes unstable and characterized by a continuous interplay of ruptures and resolutions that characterize the collaborative therapeutic action. Furthermore, it is worth noting that in the last sessions of the clinical process, in line with the $U$ shaped trend, the increase of the Session Quality Index can be interpreted as the dyad's approach to the conclusion of therapy, leading to the

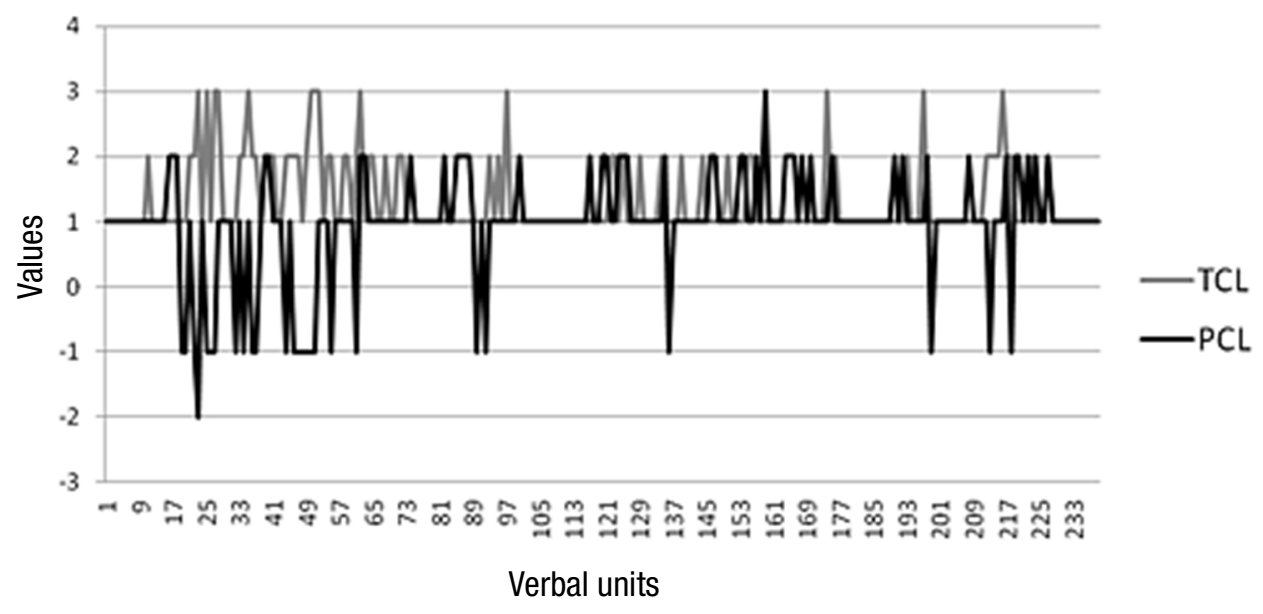

Figure 2. Patient and therapist collaboration levels in session 7. PCL $=$ Patient collaborative level. $\mathrm{TCL}=$ Therapist collaborative level. 
diminishing of their commitment in maintaining a strongly collaborative relationship.

In summary, Session Quality Index shows a non linear trend in therapeutic relationship collaborative levels and the results fit TA clinical theory which sees therapeutic work as a matter of rupture and resolution management: as Horvath (2005) suggested "The majority of the available research is based on the assumption that a positive alliance has the same quality over the length of treatment. Progressive enrichment and complexity is a characteristic of all intimate relationships over time, so why should we assume that this is not the case in therapy?" (p. 5).

The description of the clinical process mentioned above is consistent with the second hypothesis of the present work: as hypothesized, the data from the initial phase of the therapy shows a different relational pattern in terms of patient and therapist quality of interventions, compared to the other phases. Furthermore, we can see that sessions 1 to 4 are characterized by an inverse correlation, namely the greater the number of patient's non collaborative interventions, the fewer the number of positive therapist interventions, and viceversa, the fewer the number of non collaborative interventions, the greater the number of positive therapist interventions. Such unexpected results could be interpreted as the expression of a progressive synchronization between patient and therapist for a common therapeutic framework in which the clinical work can be carried on safely. These results, on the other hand, are fully consistent with STDP theory of tecnique where, as claimed by Flegenheimer (1982), the TA has to be solicited from the first sessions in order to encourage the emergence of clinically significant material. Then in the following sessions the correlation becomes positive, as an expression of a TA synchrony between patient and therapist, namely the reciprocal management of the therapeutic work, which may the expression of a clinical mutual attunement.

In summary, consistently with our second hypothesis, our results highlight a qualitatively different pattern in patient and therapist intervention in the management of TA at the beginning of the clinical work. In some ways this perspective is no different from the literature concerning the higher level in TA for good outcome clinical processes at the beginning of therapy (Horvath \& Bedi, 2002; Luborsky, 1994).

Finally the analysis of the session identified as a "high impact session" has allowed us to highlight some interesting aspects regarding the third hypothesis. Microprocess analysis of session 7 shows a highly irregular trend with a crisis of the alliance reflected by a concentration of ruptures in the initial phase. It's worth noting that the interplay of rupture and resolutions happens mainly in the beginning of the session, where the patient challenges the therapeutic bond and the therapist is engaged in managing the bond in order to promote its elaboration. This trend reflects the therapist's STPD directive technique. The subsequent ver- bal units of the session, characterized by a reduction of ruptures and an increase in collaborative processes, are made possible thanks to the first phase. Such a process in a certain sense could be characteristic of the entire psychotherapy, where the sessions at the beginning may represent the initial part of the high impact session needed to obtain a good therapeutic climate (Safran, Muran, \& Eubanks-Carter, 2011). This idea of reflecting the whole process in microprocess analysis is not new in psychotherapy research literature (Dagnino, Krause, Perez, Valdez, \& Tomicic, 2012) and could be conceived as the reproduction of the same intersubjective negotiation dynamic (Gennaro, 2011; Gennaro, et al., 2010; Salvatore, Gelo, Gennaro, Manzo, \& AlRadaideh, 2010) both at micro and macro level.

\section{Conclusion}

The present work, through a micro and macro TA analysis, explored formal features of TA, not taken into consideration by previous STDP literature: starting from three different research hypotheses we have analyzed the clinical process of a good STDP outcome in terms of formal characteristics of TA, describing the whole process, analyzing the role of early sessions for the development a positive prognostic collaborative climate, and an in-depth analysis of the collaborativenon collaborative features of a high impact session.

The results highlighted the complex (hidden) process of rupture-and-resolution underlying general TA trends usually identified in the literature. In fact, if on the one hand we highlighted the plausibility of thinking of TA in terms of quadratic trends, and the different role of TA in the early therapeutic stage according to STDP theory, on the other hand the microprocess analysis verified that the quality of the relationship between patient and therapist could arise as the result of a continuous interplay between reparation and rupture in TA. This way of looking at the therapeutic process emphasizes the intersubjective matrix through which the clinical events can be read and analyzed. Clinical process, and TA as a part of it, is a matter of unavoidable, and perhaps desirable, rupture processes, which allow the therapeutic process to evolve.

Of course, we are aware of the limitations of the present work: the single case design, and the mainly descriptive nature of the work, which does not provide information concerning causation between micro and macro processes. In order to deal with these limitations, a future goal is to apply this methodology in an extensive way to long-term psychotherapy and to study microprocesses in order to distinguish a shortterm approach from a medium-or a long-term one. A further goal is to verify whether the features of the TA, detected both at micro and macro level, are reflected in terms of the intersubjective dynamic of sensemaking (Salvatore, Gennaro, Auletta, Grassi, \& Rocco, 2011), in terms of different transition patterns of content exchanged in clinical treatment. Such results could be a further step towards the identification 
of a general theoretical model regarding clinical exchange (Gennaro, 2011; Gennaro, Gonçalves, Mendes, Ribeiro, \& Salvatore, 2011; Nitti, Ciavolino, Salvatore, \& Gennaro, 2010; Salvatore et al., 2010) that can take into account both intraindividual and interindividual aspects embedded in clinical exchange.

Despite certain limitations, the present work represents a step towards a general model of clinical intervention focusing on the role played by TA in a basic trans-theoretically acknowledged construct.

\section{References}

Ackerman, S., \& Hilsenroth, M. (2001). A review of therapist characteristics and techniques negatively impacting the therapeutic alliance. Psychotherapy, 38(2), 171-185. doi: 10.1037//0033-3204.38.2.171

Ackerman, S., \& Hilsenroth, M. (2003). A review of therapist characteristics and techniques positively impacting the therapeutic alliance. Clinical Psychology Review, 23(1), 1-33. doi: $10.1016 / \mathrm{S} 0272-7358(02) 00146-0$

Alexander, L. B., \& Luborsky, L. (1986). The Penn Helping Alliance Scales. In L. S. Greenberg \& W. M. Pinsof (Eds.), The Psychotherapeutic Process: A Research Handbook (pp. 325366). New York: Guilford Press.

Bordin, E. S. (1975). The working alliance: Basis for a general theory of psychotherapy. Paper presented at Annual Meeting of the Society for Psychotherapy Research. Washington, DC

Bordin, E. S. (1979). The generalizability of the psychoanalytic concept of the working alliance. Psychotherapy: Theory, Research and Practice, 16(3), 252-260. doi: 10.1037/h0085885

Castonguay, L. G., Costantino, M. J., \& Grosse-Holtforth, M. (2006). The working alliance: Where are we and where should we go? Psychotherapy: Theory, Research, Practice, Training, 43(3), 271-279. doi: 10.1037/0033-3204.43.3.271

Colli, A., \& Lingiardi, V. (2009). The Collaborative Interactions Scale. A new transcript-based method for the assessment of therapeutic alliance ruptures and resolution in psychotherapy. Psychotherapy Research, 19(6), 718-734. doi: 10.1080/10503300903121098

Dagnino, P., Krause, M., Perez, C., Valdez, N., \& Tomicic, A. (2012). The evolution of communicative intentions during change episodes and throughout the therapeuthic process. Research in Psychotherapy: Psychopathology, Process and Outcome, 15(2), 75-86. doi: 10.7411/RP.2012.008

Davanloo, H. (1980). Short-Term Dynamic Psychotherapy. New York: Jason Aronson.

Davanloo, H. (1990). Unlocking the Unconscious. Selected Papers of Habib Davanloo. New York: Wiley.

De Bei, F., \& Montorsi, A. (2013). Interaction structure and transferential pattern in a brief psychotherapy: A single-case study. Research in Psychotherapy: Psychopathology, Process and Outcome, 16(1), 24-32. doi: 10.7411/RP.2013.004

de Roten, Y., Fischer, M., Drapeau, M., Beretta, V., Kramer, U., Favre, N., \& Despland, J. N. (2004). Is one assessment enough? Patterns of helping alliance development and outcome. Clinical Psychology \& Psychotherapy, 11(5), 324-331. doi: $10.1002 /$ cpp.420

Derogatis, L. R. (1983). Administration, scoring, and procedures: Manual for the revised version. Baltimore: Clinical Psychometric Research.

Despland, J. N., de Roten, Y., Drapeau, M., Currat, T., Beretta, V., \& Kramer, U. (2009). The role of alliance in the relationship between therapist competence and outcome in brief psychodynamic psychotherapy. Journal of Nervous and Mental Disease, 197(5), 362-367. doi: 10.1097/NMD.0b013e3181a20849

Flegenheimer, W. V. (1982). Techniques of Brief Psychotherapy.
New York: Jason Aronson.

Fosha, D. (2000). The Transforming Power of Affect. New York: Basic Books.

Gaston, L., Piper, W., Debbane, E., Bienvenu, J. P., \& Garant, J. (1994). Alliance and technique for predicting in short- and long-term analytic psychotherapy. Psychotherapy Research, 4(2), 1221-1135. doi: 10.1080/10503309412331333952

Gelso, C. J., \& Carter, J. A. (1985). The relationship in counseling and psychotherapy: Components, consequences, and theoretical antecedents. The Counseling Psychologist, 13(2), 155-243. doi: 10.1177/0011000085132001

Gennaro, A. (2011). The building of models as pathway to understand the therapeutic process. Integrative Psychological and Behavioral Science, 45(3), 355-365. doi: 10.1007/s12124-011-9181-8

Gennaro, A., Al-Radaideh, A., Gelo, O., Manzo, S., Nitti, M., \& Salvatore, S. (2010). Modelling the psychotherapy process as a meaning-making dynamics. The Two Stage Semiotic Model (TSSM) and the Discourse Flow Analyzer (DFA). In S. Salvatore, J. Valsiner, A. Gennaro \& J. B. Traves Simon (Eds.), YIS: Yearbook of idiographic science (Vol. 2, pp.131172). Roma: Firera Publishing Group.

Gennaro, A., Gonçalves, M., Mendes, I., Ribeiro, A., \& Salvatore, S. (2011). Dynamics of sense-making and development of the narrative in the clinical exchange. Research in Psychotherapy: Psychopathology, Process and Outcome, 14(1), 90-120.

Golden, B., \& Robbins, S. (1990). The working alliance within time-limited psychotherapy: A case analysis. Professional Psychology: Theory, Research and Practice, 21(6), 476-481. doi: 10.1037/0735-7028.21.6.476

Greenacre, P. (1954). The role of transference. Journal of the American Psychoanalytic Association, 2(4), 671-684. doi: 10.1177/000306515400200406

Greenson, R. R. (1967). The Technique and Practice of Psychoanalysis. New York: International Universities Press.

Horvath, A. O. (2005). The therapeutic relationship: Research and theory. Psychotherapy Research, 15(1-2), 3-7. doi: $10.1080 / 10503300512331339143$

Horvath, A. O., \& Bedi, R. P. (2002). The alliance. In J. Norcross (Ed.), Psychotherapy Relations that Work (pp. 37-70). New York: Oxford.

Horvath, A. O., \& Marx, R. W. (1991). The development and decay of the working alliance during time-limited counseling. Canadian Journal of Counseling, 24(4), 240-259.

Kivlighan, D. M. J., \& Shaughnessy, P. (1995). Analysis of the development of the working alliance using hierarchical linear modeling. Journal of Counseling Psychology, 42(3), 338349. doi: 10.1037//0022-0167.42.3.338

Kivlighan, D. M. J., \& Shaughnessy, P. (2000). Patterns of working alliance development: a typology of client's working alliance ratings. Journal of Counseling Psychology, 47(3), 362371. doi: 10.1037//0022-0167.47.3.362

Kramer, U., de Roten, Y., Beretta, V., Michel, L., \& Despland, J. N. (2009). Alliance patterns over the course of short-term dynamic psychotherapy: The shape of productive relationships. Psychotherapy Research, 19(6), 699-706. doi: 10.1080/10503300902956742

Landis, J. R., \& Koch, G. G. (1977). The measurement of observer agreement for categorical data. Biometrics, 33(1), 159174. doi: $10.2307 / 2529310$

Luborsky, L. (1994). Therapeutic alliance as predictor of psychotherapy outcomes: Factors explaining the predictive process. In A. O. Horvath \& L. S. Greenberg (Eds.), The Working Alliance: Theory, Research and Practice (pp. 38-50). New York: John Wiley \& Sons.

Mann, J. (1973). Time Limited Psychotherapy. Cambridge, Massachusetts and London, England: Harvard University Press.

Marmar, C. R., Weiss, D. S., \& Gaston, L. (1989). Toward the validation of the California Therapeutic Alliance Rating Scale. 
Psychological Assessment, 1(1), 46-52. doi: 10.1037/10403590.1.1.46

Mergenthaler, E., Freni, S., Giampieri, E., \& Ferrari, R. (1998). Regole standardizzate di trascrizione delle sedute di psicoterapia [Standardized rules of transcription of psychotherapy sessions]. Ricerca in Psicoterapia, 1(1), 29-46.

Muran, J. C., Safran, J. D., Gorman, B. S., Samstag, L. W., Eubanks-Carter, C., \& Winston, A. (2009). The relationship of early alliance ruptures and their resolution to process and outcome in three time-limited psychotherapies for personality disorders. Psychotherapy: Theory, Research, Practice, Training, 46(2), 233-248. doi: 10.1037/a0016085

Nitti, M., Ciavolino, E., Salvatore, S., \& Gennaro, A. (2010). Analyzing psychotherapy process as intersubjective sensemaking: An approach based on discourse analysis and neural networks. Psychotherapy Research, 20(5), 546-563. doi: $10.1080 / 10503301003641886$

Norcross, J. C. (2011). Psychotherapy Relationships That Work: Evidence-Based Responsiveness ( $2^{\text {nd }}$ ed.). New York: Oxford University Press.

Owen, J., \& Hilsenroth, M. J. (2011). Interaction between alliance and technique in predicting patient outcome during psychodynamic psychotherapy. Journal of Nervous and Mental Disease, 199(6), 384-389. doi: 10.1097/NMD.0b013e31821cd28a

Patton, M. J., Kivlighan, D. M. J., \& Multon, K. D. (1997). The missouri psychoanalytic counseling research project: Relation of changes in counseling process to client outcomes. Journal of Counseling Psychology, 44(2), 189-208. doi: 10.1037//0022-0167.44.2.189

Raue, P. J., Goldfried, M. R., \& Barkham, M. (1997). The therapeutic alliance in psychodynamic-interpersonal and cognitivebehavioral therapy. Journal of Consulting and Clinical Psychology, 65(4), 582-587. doi: 10.1037//0022-006X.65.4.582

Rocco, D., De Bei, F., \& Mariani, R. (2013). Introduction to the special issue. Research in Psychotherapy: Psychopathology, Process and Outcome, 16(1), 1-5. doi: 10.7411/RP.2013.001

Safran, J. D., \& Muran, J. C. (Eds.). (1998). The therapeutic alliance in short-term psychotherapy. Washington, DC: American Psychological Association Publications.

Safran, J. D., \& Muran, J. C. (2000). Negotiating the therapeutic alliance. New York: Guilford Press.
Safran, J. D., Muran, J. C., \& Eubanks-Carter, C. (2011). Repairing alliance ruptures. In J. C. Norcross (Ed.), Psychotherapy Relationships that Work (pp. 224-238). New York: Oxford University Press. doi: 10.1037/a0022180

Salvatore, S., Gelo, O., Gennaro, A., Manzo, S., \& Al-Radaideh, A. (2010). Looking at psychotherapy as an intersubjective dynamic of sensemaking. A case study with Discourse Flow Analysis. Journal of Constructivist Psychology, 23(3), 195230. doi: 10.1080/10720531003765981

Salvatore, S., Gennaro, A., Auletta, A., Grassi, R., \& Rocco, D. (2011). Dynamic Mapping of the Structures of Content in Clinical Settings (DMSC). A new coding system for analyzing the patient's narratives. Psychology and Psychotherapy: Theory, Research and Practice, 85(4), 391-423. doi: 10.1111/j.2044-8341.2011.02038.x

Sexton, H. C., Hembre, K., \& Kvarme, G. (1996). The interaction of the alliance and therapy microprocess: A sequential analysis. Journal of Consulting and Clinical Psychology, 64(3), 471-480. doi: 10.1037//0022-006X.64.3.471

Shrout, P. E., \& Fleiss, J. L. (1979). Intraclass correlations: Uses in assessing rater reliability. Psychologycal Bullettin, 86(2), 420-428. doi: 10.1037//0033-2909.86.2.420

Stevens, C. L., Muran, J. C., Safran, J. D., Gorman, B. S., \& Winston, A. (2007). Levels and patterns of the therapeutic alliance in brief psychotherapy. American Journal of Psychotherapy, 61(2), 109-129.

Stiles, W. B., Glick, M. J., Osatuke, K., Hardy, E. G., Shapiro, D. A., Agnew-Davies, R., \& Barkham, M. (2004). Patterns of alliance development and the rupture repair hypothesis: Are relationship U-shaped or V-shaped? Journal of Counseling Psychology, 51(1), 81-92. doi: 10.1037/0022-0167.51.1.81

Westen, D., Shedler, J., \& Lingiardi, V. (2003). La valutazione della personalità con la SWAP-200 [Personality assessment with SWAP-200]. Milano: Raffaello Cortina.

Received May 31, 2012

Revision received June 19, 2013

Accepted July 29, 2013 